\title{
Correction to: A formulation of neem and hypericum oily extract for the treatment of the wound myiasis by Wohlfahrtia magnifica in domestic animals
}

\author{
Fiorella Carnevali ${ }^{1}$. Delia Franchini ${ }^{2}$ (D) Domenico Otranto ${ }^{3} \cdot$ Annunziata Giangaspero $^{4} \cdot$ Antonio Di Bello $^{2}$. \\ Stefano Ciccarelli ${ }^{2} \cdot$ Krzysztof Szpila $^{5} \cdot$ Carmela Valastro $^{2} \cdot$ Andrew Stephen van der Esch $^{1}$
}

Published online: 27 July 2019

(C) Springer-Verlag GmbH Germany, part of Springer Nature 2019

\section{Correction to: Parasitology Research} https://doi.org/10.1007/s00436-019-06375-x

The given names and family names of the authors of the originally published version of this article was inadvertently interchanged. Correct presentation of the author names are presented here.

The original article has been corrected.

Publisher's note Springer Nature remains neutral with regard to jurisdictional claims in published maps and institutional affiliations.

The online version of the original article can be found at https://doi.org/ 10.1007/s00436-019-06375-x

Delia Franchini

delia.franchini@uniba.it

1 TECS - Division, SSPT Department, Enea Centro Ricerche Casaccia, via Anguillarese 301, Rome, Italy

2 Department of Veterinary Medicine, Section of Surgery and Internal Medicine, University of Bari, Bari, Italy

3 Department of Veterinary Medicine, Section of Parasitology, University of Bari, Bari, Italy

4 Department of Agriculture Science, Food and Environment, University of Foggia, Foggia, Italy

5 Department of Ecology and Biogeography, Nicolaus Copernicus University, Torun, Poland 